\title{
Synthesis and Evaluation of Mycophenolic Acid Derivatives as Potential Anti-Toxoplasma Gondii Agents
}

\section{Fan-Fan Shang}

Yanbian University

Mei-Yuan Wang

Yanbian University

Jiang-Ping Ai

Yanbian University

Qing-Kun Shen

Yanbian University

Hong-Yan Guo

Yanbian University

Chun-Mei Jin

Yanbian University

Fen-Er Chen

Fudan University

Zhe-Shan Quan

Yanbian University

Lili Jin

Yanbian University

Changhao Zhang ( $\sim$ zhangch@ybu.edu.cn )

Yanbian University

\section{Research Article}

Keywords: Mycophenolic acid, Synthesis, Toxoplasma gondii, in vitro, in vivo

Posted Date: August 10th, 2021

DOI: https://doi.org/10.21203/rs.3.rs-780085/v1

License: (c) (i) This work is licensed under a Creative Commons Attribution 4.0 International License.

Read Full License 


\section{Abstract}

Nineteen mycophenolic acid (MPA) derivatives were designed and synthesized, and their antiToxoplasma activity evaluated for the first time. Among them, N-propylimidazole-modified compound E5 demonstrated the strongest activity, and the $\mathrm{IC}_{50}$ against HFF-1 (Human Foreskin Fibroblasts-1) cells following infection with $T$. gondii is $80.9 \mu \mathrm{M}$ (MPA-211.5 $\mu \mathrm{M}$ ) and its selectivity value is 2.2 (MPA-1.2). In vivo experiments, E5 significantly inhibited the proliferation of tachyzoites in the abdominal cavity of mice acutely infected with $T$. gondii (inhibition rates $46.7 \%$ ), and this inhibitory effect was greater than that of spiramycin (inhibition rates $31.3 \%$ ) and MPA (inhibition rates 15.9\%), this indicated that E5 had significant protective effects on the host during acute Toxoplasma infection. In addition E5 significantly reduced the levels of alanine aminotransferase (ALT) and aspartate aminotransferase (AST) in the serum of infected mice, significantly increased the level of glutathione (GSH) in the liver, and significantly reduced the level of malondialdehyde (MDA), indicating that it has a significant hepatoprotective effect against $T$. gondii infection. Similarly, E5 can relieve hepatomegaly and splenomegaly induced by acute Toxoplasma infection. Spiramycin aggravated appetite loss in infected mice, while E5 did not. In summary, the results indicated that E5 has potential as a candidate anti-T. gondii drug.

\section{Introduction}

Toxoplasma gondii is an obligate intracellular parasite with a wide variety of hosts, including humans, livestock, and marine mammals, and can cause zoonotic toxoplasmosis ${ }^{[1]}$. Following infection, individuals with normal immune function show no obvious symptoms, while those with insufficient or low immune function may display extensive pathological damage or even death. In pregnant females, infection can lead to miscarriage, premature delivery, stillbirth, and teratogenesis ${ }^{[2,3]}$. Toxoplasma gondii can also infect domestic animals, such as pigs, cattle, and sheep, and often infects companion animals, such as dogs, cats, and rabbits. The pathogen also causes huge economic losses to the livestock industry, and T. gondii is detrimental to food safety and human health ${ }^{[4,5]}$. At present, the main treatment for toxoplasmosis is still drug therapy, mainly including pyrimethamine, sulfadiazine, spiramycin and the combined use of sulfadiazine and pyrimethamine. Although there has been some success with antiToxoplasma drugs, many problems remain. For example, the use of anti-Toxoplasma drugs can lead to adverse reactions, such as allergies, bone marrow suppression, and increased risk of liver and kidney complications. In addition, these drugs are not suitable for use during pregnancy ${ }^{[6-8]}$. Therefore, there is an urgent need for the development of anti-Toxoplasma drugs with high efficiency and low toxicity.

The immunosuppressant mycophenolate mofetil has been used widely to prevent and treat the acute rejection of transplanted organs. Mycophenolate mofetil exerts immunosuppressive activity via conversion into mycophenolic acid (MPA, Fig. 1) in the body ${ }^{[9-11]}$. MPA is a meroterpenoid consisting of an acetate-derived phthalide nucleus and a terpene-derived side chain, which possesses a range of biological properties, including antifungal ${ }^{[12]}$, antivira ${ }^{[13]}$, anti-inflammatory ${ }^{[14]}$, and antitumor ${ }^{[15]}$ properties. In addition, MPA is a potent non-competitive inhibitor of inosine nucleotide dehydrogenase 
inosine monophosphate dehydrogenase (IMPDH). However, IMPDH is essential for the purine metabolism of Toxoplasma gondii. More importantly, MPA has been used extensively in strategies for the generation of genetically modified strains of Toxoplasma gondii ${ }^{[16]}$. To our knowledge, there have been no reports on the activity of MPA derivatives against $T$. gondii. Therefore, in this study, we modified the structure of MPA to obtain high-efficiency and low-toxicity anti-Toxoplasma drugs.

Studies have reported that the lactone ring and aromatic methyl group in the structure of MPA are essential to its activity ${ }^{[17]}$. Therefore, in this study, these two groups were retained, and the carboxyl position of the structure was modified to introduce nitrogen-containing pharmacophores and convert it into an amide. The amide group can be used as a hydrogen donor, reducing the sensitivity of enzymatic hydrolysis and improving the stability of the compound in vivo and in vitro ${ }^{[18]}$. Amino acids are the basic biological and functional units of proteins; and they play a vital role in human metabolism and exert a wide range of biological activities, including antibacterial[ ${ }^{[19,20]}$, anticancer ${ }^{[21]}$, anti-tuberculosis ${ }^{[22]}$, antiinflammatory ${ }^{[23,24]}$, and anti-parasitic ${ }^{[25,26]}$ activities. In addition, they improve both the solubility and bioavailability of the drugs ${ }^{[27-29]}$. Studies have reported that nitrogen-containing heterocycles, such as benzylamine, pyrrolidine, piperazine, morpholine, and imidazole, are an important class of active fragments against $T$. gondii ${ }^{[30-32]}$. In addition, active fragments with these functions also include benzylamine and fatty amines ${ }^{[29]}$. Therefore, we designed and synthesized five series of MPA derivatives and evaluated their anti-Toxoplasma activity. Subsequently, we selected the most active derivative E5, at the cellular level for subsequent in vivo activity studies to find highly efficient and low-toxicity MPA derivatives with anti-Toxoplasma activity.

\section{Results And Discussion}

\subsection{Chemistry}

The synthetic route for targets is shown in Scheme 1. MPA as a starting material and all target compounds were obtained by an amide condensation reaction with different amino compounds catalysed by 1-(3-dimethylaminopropyl)-3-ethylcarbodiimide hydrochloride (EDCl) and Biphenyl-4-

amidoxime ( $\mathrm{HOBt}$ ) in anhydrous $\mathrm{CH}_{2} \mathrm{Cl}_{2}$ at $0^{\circ} \mathrm{C}^{[33,34]}$. TLC was used to monitor the reactions, and the final products were purified using silica gel chromatography to obtain the target compounds. Among them, compounds A1, A3, A4, C1, C2, E3 have been reported ${ }^{[35,36]}$. All compounds were confirmed by ${ }^{1} \mathrm{H}$ NMR, ${ }^{13} \mathrm{C}$ NMR, and high-resolution mass spectrometry.

\subsection{Biological evaluation}

\subsubsection{In vitro anti-T. gondii activity and Structure-activity relationship (SAR) study}

The thiazolyl blue (MTT) colorimetric method was used to determine the cytotoxicity and in vitro antitachyzoites activity ( $T$. gondii, RH strain) of all compounds at different concentrations $(10-1000 \mu \mathrm{M})$ in an activity test in host cells (Human Foreskin Fibroblasts-1 cells) ${ }^{[37]}$. 
The in vitro anti-Toxoplasma activity is shown in Table $1 . \mathrm{IC}_{50}{ }^{\mathrm{a}}$ is the half-inhibitory concentration of the compound against HFF- 1 cells, which reflects its cytotoxicity. $\mathrm{IC}_{50} \mathrm{~b}$ is the half-inhibitory concentration of the compound against HFF-1 cells following infection with $T$. gondii; this value reflects the anti- $T$. gondii activity of the compound. The selectivity index $\left(\mathrm{SI}=I \mathrm{IC}_{50} \mathrm{a} / \mathrm{IC}_{50} \mathrm{~b}\right)$ provides a screening reference for subsequent in vivo experiments ${ }^{[18]}$. In this experiment, MPA was used as the lead compound, different types of pharmacophores were introduced, and five series of compounds were designed and synthesised with spiramycin being used as the positive control drug. The anti-Toxoplasma activity of MPA in vitro was greater than that of spiramycin, which has strong anti-Toxoplasma potential. In the compound A series, different substituted aromatic hydrocarbons were introduced into the MPA. The in vitro anti-Toxoplasma activity of all compounds was lower than that of lead, however it is worth noting that most of the compounds showed very low cytotoxicity, except for $\mathbf{A} \mathbf{1}$, the selectivity of all compounds has been improved, and their SI value was higher than that of MPA and the positive control drugs. In this series, the preliminary structure-activity relationship demonstrated that the introduction of electron-withdrawing groups or electron-donating groups on the benzene ring, or appropriately extended the length of the aliphatic chain, increased the in vitro anti-Toxoplasma activity. In the compound B series, different alkanes were introduced into the MPA. Compared with that of the lead, all compounds demonstrated reduced in vitro anti-Toxoplasma activity and a lower SI value. This suggests that the introduction of alkanes on MPA decreased the effectiveness against $T$. gondii. The compound $\mathbf{C}$ series was endowed with different amino acid methyl ester fragments into the lead. In this group, compound $\mathbf{C} 1$ and lead exhibited similar in vitro anti-Toxoplasma activity. The SI value of compound $\mathbf{C 2}$ was 1.6 , which was better than that of the lead and the positive control drugs. In the compound $\mathbf{D}$ series, four different amine compounds were connected to MPA. Unfortunately, the in vitro anti-Toxoplasma activity and SI values of all compounds were not ideal. The compound $\mathbf{E}$ series are connected to different heterocyclic compounds, and the in vitro anti-Toxoplasma activity of compounds E3, E4, and E5 were improved. Compound E5 obtained by the introduction of an $N$-propylimidazole fragment to the lead, and this compound presented the strongest in vitro anti-Toxoplasma activity among all series, and the $\mathrm{IC}_{50}$ against HFF-1 cells following infection with $T$. gondii is $80.9 \mu \mathrm{M}$. In addition, it has the highest selectivity in this article (SI: 2.2), its $\mathrm{IC}_{50}$ and SI values were significantly better than those of the positive control drug ( $\mathrm{IC}_{50}: 233.4 \mu \mathrm{M}$; SI:1.2) and mycophenolic acid (IC $\mathrm{I}_{50}: 211.5 \mu \mathrm{M}$; SI:1.2), which indicates that it has the highest selectivity index while maintaining in vitro anti-Toxoplasma activity and has some research value. Therefore, in this experiment, compound $\mathbf{E 5}$ was selected for the subsequent evaluation of anti-T. gondii activity in vivo.

\subsubsection{Effect of compounds $E 5$ on the inhibition of tachyzoites in vivo}

The number of $T$. gondii tachyzoites in the abdominal cavity of mice reflects the therapeutic effects of a compound $^{[38]}$. As shown in Table 2 and Figure 2, compared with that of the model group, after treatment with $100 \mathrm{mg} / \mathrm{kg}$ of different compounds, 
the inhibition of intraperitoneal tachyzoites in mice in the MPA treatment group was only $15.9 \%$. Interestingly, intraperitoneal tachyzoite inhibition in the E5 treatment groups was $46.7 \%$, respectively, and there were significant differences compared with the model group $(p<0.001)$. Therefore, compound E5 significantly reduced the number of $T$. gondii tachyzoites in the abdominal cavity of Kunming mice and their activity exceeded that of the positive control spiramycin, indicating that E5 is effective against acute T. gondii infection. The protective effect on the host during infection was significant.

\subsubsection{Liver and spleen indices.}

A large number of studies have shown that in the acute infection model obtained by giving a virulent strain of Toxoplasma gondii through the abdominal cavity of mice, it is found that the liver is an important place for toxoplasma replication. Toxoplasma gondii is produced in large quantities in liver cells, which damages the liver cells ${ }^{[39]}$, leading to liver pathological changes such as hepatomegaly, hepatitis, and necrosis in the infected host. Hepatic function and metabolism reduce when hepatocytes are damaged. Therefore incomplete metabolized substances are produced in liver, resulting in an increase on the liver index ${ }^{[40]}$. The level of the liver index reflects the degree of liver damage ${ }^{[41]}$. Moreover, the spleen is an important immune organ, which plays a significant role in the immune response, including the response to antigenic substances in the blood. Both humoral and cellular immunity can induce changes in the organizational structure of the spleen. To a certain extent, an increase in the spleen index reflects changes in spleen structure and function ${ }^{[42,43]}$. Therefore, the liver and spleen indices can be used to evaluate the protective effects of drugs on organs. As shown in Figure 3, compared with those in the normal group, the liver and spleen indices of the toxo group increased, indicating that $T$. gondii induces liver and spleen damage in mice. Compound E5 was able to alleviate hepatomegaly and splenomegaly caused by acute Toxoplasma infection.

\subsubsection{ALT and AST in serum}

The levels of alanine aminotransferase (ALT) and aspartate aminotransferase (AST) in serum are used to evaluate liver function. In this experiment, the liver toxicity of each compound was evaluated by determining the levels of ALT and AST in the serum of mice ${ }^{[44]}$. As shown in Figure 4, compared with those in the normal group, the ALT and AST levels in the toxo group were significantly increased, and this was alleviated in the treatment group. Notably, compound E5 was able to significantly reduce the levels of ALT and AST in the serum of infected mice. These results show that compound E5 is effective in treating $T$. gondii infection and preventing hepatotoxicity caused by $T$. gondii infection.

\subsubsection{GSH and MDA}

Glutathione (GSH) is a small-molecule peptide composed of three amino acids that is involved in detoxification, its main functions are to scavenge free radicals, resist oxidation, and resist aging ${ }^{[45]}$. According to reports in the literature, Toxoplasma gondii infection can cause oxidative stress and immunosuppressive reactions ${ }^{[46]}$. During the infection of Toxoplasma gondii, the production of reactive 
oxygen species ROS increases, and the excessive production of ROS can cause cell and tissue damage ${ }^{[47,48]}$. GSH can protect cells from oxidative damage by eliminating superoxide anion free radicals. And its levels in mice exposed to Toxoplasma gondii are significantly reduced ${ }^{[49,50]}$. As shown in Figure $5 \mathrm{~A}$, compared with the normal group, the GSH content of the toxo group was significantly reduced, indicating that $T$. gondii infection can decrease the GSH content in mice. Interestingly, compared with that of the model group, GSH content was increased in mice in the treatment group, and the activity of compound E5 was greater than that of the positive control spiramycin and the lead compound MPA. This indicates that compound E5 is effective at inhibiting the growth of $T$. gondii in mice and has a strong antioxidant effect.

Malondialdehyde (MDA), one major product of lipid peroxidation, significantly increased in mice exposed to T. gondi ${ }^{[51]}$. As shown in Figure $\mathbf{5} \mathbf{B}$, compared with that of the normal group, the MDA content in the toxo group significantly increased as we predicted, while spiramycin, MPA and E5 significantly reduced MDA content. Among them, compound E5 had the same curative effect as spiramycin and was better than lead MPA.

\subsubsection{Effects of compounds on the weight of mice}

To further evaluate the effects of the test compounds on mice, the weight change of animals during treatment was recorded. As shown in Figure 6, compared with the normal group, mice in the toxo group lost their appetite due to $T$. gondii infection, resulting in a sharp decline in body weight. However, this was exacerbated by spiramycin and MPA. Notably, compound E5 did not result in weight loss, moreover alleviated the loss of appetite in mice.

\section{Conclusions}

In this study, nineteen MPA derivatives in five series were designed and synthesised, and their antiToxoplasma activity was reported for the first time. The in vitro results demonstrated that E5 was the greatest potential and was superior to MPA and spiramycin.. The results of further in vivo experiments showed that E5 exerted an inhibitory effect on T. gondii, a strong protective effect on the liver, and could significantly alleviate splenomegaly in infected mice with limited side effects. These findings suggest that $\mathbf{E} 5$ is a potential candidate anti-T. gondii. drug.

\section{Experimental Section}

Mycophenolic acid is a natural compound, purchased from Chengdu Refines Biotechnology Co., Ltd., with a purity of $98 \%$. The organic reagents required for the experiment are all analytically pure, and other chemicals are purchased from Aladdin reagent. The obtained products were monitored by thin-layer chromatography to check the progress of the reaction, and separation was carried out using a chromatography column. The melting point of the target product was measured in an open capillary (the temperature is not corrected); ${ }^{1} \mathrm{H}-\mathrm{NMR}$ and ${ }^{13} \mathrm{C}$-NMR used the chemical shift of TMS as the zero point, 
measured by AV-300 nuclear magnetic resonance instrument; The high resolution mass spectrum was measured by ESI mass spectrometer.

\subsection{General procedure for the reaction of mycophenolic acid with different intermediates containing- amino}

Mycophenolic acid (64 mg, $0.2 \mathrm{mmol})$, different amine compounds $(0.24 \mathrm{mmol})$, carboxylic mixture 1Ethyl-3-(3-dimethylaminopropyl) carbodiimide hydrochloride (EDCl) $(114.7 \mathrm{mg}, 0.6 \mathrm{mmol})$ and catalyst Biphenyl-4-amidoxime (HOBt) $(84.8 \mathrm{mg}, 0.4 \mathrm{mmol})$ were taken in a $25 \mathrm{ml}$ round bottom flask, and $5 \mathrm{ml}$ dichloromethane as solvent, stirred at $0{ }^{\circ} \mathrm{C}$ for $4-6 \mathrm{~h}$, progress of reaction was confirmed by TLC, the final products were purified using silica gel chromatography, and all the target compounds were obtained, which are white powder in appearance, and the yield is $48 \%-79 \%$.

\subsection{1 (E)-N-benzyl-6-(4-hydroxy-6-methoxy-7-methyl-3-oxo-1,3-dihydroisobenzofuran-5-yl)-4-methylhex-4- enamide (A1)}

White powder; yield 52\%; m.p. 96-98 ${ }^{\circ} \mathrm{C} .{ }^{1} \mathrm{H}$ NMR $\left(300 \mathrm{MHz}, \mathrm{CDCl}_{3}, \mathrm{ppm}\right) \delta 7.67(\mathrm{~s}, 1 \mathrm{H}), 7.35-7.30(\mathrm{~m}, 2 \mathrm{H})$, 7.27-7.20 (m, 3H), $5.77(\mathrm{brs}, 1 \mathrm{H}), 5.32(\mathrm{t}, J=8.1 \mathrm{~Hz}, 1 \mathrm{H}), 5.19(\mathrm{~s}, 2 \mathrm{H}), 4.41(\mathrm{~d}, J=5.7 \mathrm{~Hz}, 2 \mathrm{H}), 3.77(\mathrm{~s}, 3 \mathrm{H})$, $3.40(\mathrm{~d}, J=6.9 \mathrm{~Hz}, 2 \mathrm{H}), 2.36(\mathrm{~s}, 4 \mathrm{H}), 2.15(\mathrm{~s}, 3 \mathrm{H}), 1.84(\mathrm{~s}, 3 \mathrm{H}) .{ }^{13} \mathrm{C} \mathrm{NMR}\left(75 \mathrm{MHz}, \mathrm{CDCl}_{3}\right): \delta 172.91$, $172.48,163.63,153.59,144.04,138.33,134.60,128.62$ (2C), 127.58 (2C), 127.36, 123.06, 122.00, 116.76, $106.40,70.03,61.01,43.48,35.27,35.09,22.62,16.12,11.54$. ESI-HRMS $(m / z)$ calcd for $\mathrm{C}_{24} \mathrm{H}_{28} \mathrm{NO}_{5}{ }^{+}$ $[\mathrm{M}+\mathrm{H}]^{+}:$: 410.19620, found: 410.19528 .

\subsection{2 (E)-N-(4-fluorobenzyl)-6-(4-hydroxy-6-methoxy-7-methyl-3-oxo-1,3-dihydroisobenzofuran-5-yl)-4- methylhex-4-enamide (A2)}

White powder; yield 73\%; m.p. $156-158^{\circ} \mathrm{C} .{ }^{1} \mathrm{H}$ NMR $\left(300 \mathrm{MHz}, \mathrm{CDCl}_{3}, \mathrm{ppm}\right) \delta 7.67$ (s, $\left.1 \mathrm{H}\right), 7.19$ (dd, $J=8.4$, $5.4 \mathrm{~Hz}, 2 \mathrm{H}), 6.98(\mathrm{t}, J=8.7 \mathrm{~Hz}, 2 \mathrm{H}), 5.81$ (brs, $1 \mathrm{H}), 5.29(\mathrm{t}, J=6.9 \mathrm{~Hz}, 1 \mathrm{H}), 5.20(\mathrm{~s}, 2 \mathrm{H}), 4.37$ (d, J = $5.7 \mathrm{~Hz}$, 2H), $3.77(\mathrm{~s}, 3 \mathrm{H}), 3.40(\mathrm{~d}, J=6.9 \mathrm{~Hz}, 2 \mathrm{H}), 2.36(\mathrm{~s}, 4 \mathrm{H}), 2.15(\mathrm{~s}, 3 \mathrm{H}), 1.83(\mathrm{~s}, 3 \mathrm{H}) .{ }^{13} \mathrm{C} \mathrm{NMR}\left(75 \mathrm{MHz}, \mathrm{CDCl}_{3}\right)$ : $\delta 172.90,172.55,163.68,163.61,153.58,144.05,134.57,134.23,129.24,129.14,123.10,121.94,116.80$, $115.52,115.24,106.39,70.05,61.01,42.70,35.24,34.99,22.64,16.10,11.53$. ESI-HRMS $(\mathrm{m} / \mathrm{z}) \mathrm{calcd}$ for $\mathrm{C}_{24} \mathrm{H}_{27} \mathrm{FNO}_{5}{ }^{+}[\mathrm{M}+\mathrm{H}]^{+}: 428.18678$, found: 428.18616 .

\subsection{3 (E)-6-(4-hydroxy-6-methoxy-7-methyl-3-oxo-1,3-dihydroisobenzofuran-5-yl)-4-methyl-N-(4- methylbenzyl)hex-4-enamide (A3)}

White powder; yield 75\%; m.p. $116-118^{\circ} \mathrm{C} .{ }^{1} \mathrm{H}$ NMR $\left(300 \mathrm{MHz}, \mathrm{CDCl}_{3}, \mathrm{ppm}\right) \delta 7.68(\mathrm{~s}, 1 \mathrm{H}), 7.12(\mathrm{~s}, 4 \mathrm{H})$, $5.75(\mathrm{brs}, 1 \mathrm{H}), 5.28(\mathrm{t}, J=6.6 \mathrm{~Hz}, 1 \mathrm{H}), 5.19(\mathrm{~s}, 2 \mathrm{H}), 4.35(\mathrm{~d}, J=5.7 \mathrm{~Hz}, 2 \mathrm{H}), 3.77(\mathrm{~s}, 3 \mathrm{H}), 3.40(\mathrm{~d}, J=6.6 \mathrm{~Hz}$, 2H), $2.34(\mathrm{~s}, 7 \mathrm{H}), 2.15(\mathrm{~s}, 3 \mathrm{H}), 1.82(\mathrm{~s}, 3 \mathrm{H}) .{ }^{13} \mathrm{C} \mathrm{NMR}\left(75 \mathrm{MHz}, \mathrm{CDCl}_{3}\right): \delta 172.90,172.41,163.64,153.60$, $144.03,137.07,135.29,134.61,129.28$ (2C), 127.60 (2C), 122.99, 122.03, 116.75, 106.39, 70.03, 61.00, 
$43.25,35.29,35.14,22.62,21.07,16.12,11.55$. ESI-HRMS $(\mathrm{m} / \mathrm{z})$ calcd for $\mathrm{C}_{25} \mathrm{H}_{30} \mathrm{NO}_{5}{ }^{+}$ $[\mathrm{M}+\mathrm{H}]^{+}:$: 424.21185 , found: 424.2115 .

4.1.4 (E)-6-(4-hydroxy-6-methoxy-7-methyl-3-oxo-1,3-dihydroisobenzofuran-5-yl)-4-methyl-N-phenethylhex4-enamide (A4)

White powder; yield 70\%; m.p. 102-104 ${ }^{\circ} \mathrm{C} .{ }^{1} \mathrm{H} \mathrm{NMR}\left(300 \mathrm{MHz}, \mathrm{CDCl}_{3}, \mathrm{ppm}\right) \delta 7.69$ (brs, $\left.1 \mathrm{H}\right), 7.34-7.29$ (m, $2 \mathrm{H}), 7.25(\mathrm{~d}, J=7.2 \mathrm{~Hz}, 1 \mathrm{H}), 7.21-7.12(\mathrm{~m}, 2 \mathrm{H}), 5.49(\mathrm{brs}, 1 \mathrm{H}), 5.25(\mathrm{t}, J=6.9 \mathrm{~Hz}, 1 \mathrm{H}), 5.13(\mathrm{~s}, 2 \mathrm{H}), 3.78(\mathrm{~s}$, $3 \mathrm{H}), 3.48-3.38(\mathrm{~m}, 4 \mathrm{H}), 2.70(\mathrm{t}, J=6.9 \mathrm{~Hz}, 2 \mathrm{H}), 2.35-2.22(\mathrm{~m}, 4 \mathrm{H}), 2.14(\mathrm{~s}, 3 \mathrm{H}), 1.81(\mathrm{~s}, 3 \mathrm{H}) .{ }^{13} \mathrm{C} \mathrm{NMR}(75$ $\left.\mathrm{MHz}, \mathrm{CDCl}_{3}\right) \delta 172.92,172.55,163.66,153.59,144.09,138.92,134.57,128.67$ (2C), 128.59 (2C), 126.46, $122.81,122.05,116.77,106.38,70.02,61.01,40.53,35.66,35.22,35.05,22.61,16.13,11.55$. ESI-HRMS $(\mathrm{m} / \mathrm{z})$ calcd for $\mathrm{C}_{25} \mathrm{H}_{30} \mathrm{NO}_{5}{ }^{+}[\mathrm{M}+\mathrm{H}]^{+}: 424.21185$, found: 424.21115 .

\subsection{5 (E)-6-(4-hydroxy-6-methoxy-7-methyl-3-oxo-1,3-dihydroisobenzofuran-5-yl)-N-(4-hydroxyphenethyl)-4- methylhex-4-enamide (A5)}

White powder; yield 70\%; m.p. $112-114^{\circ} \mathrm{C} .{ }^{1} \mathrm{H} \mathrm{NMR}\left(300 \mathrm{MHz}, \mathrm{CDCl}_{3}, \mathrm{ppm}\right) \delta 7.60$ (brs, 2H), $6.92(\mathrm{~d}, J=$ $8.4 \mathrm{~Hz}, 2 \mathrm{H}), 6.77(\mathrm{~d}, J=7.2 \mathrm{~Hz}, 2 \mathrm{H}), 5.85(\mathrm{t}, J=5.7 \mathrm{~Hz}, 1 \mathrm{H}), 5.24(\mathrm{t}, J=6.9 \mathrm{~Hz}, 1 \mathrm{H}), 5.09(\mathrm{~s}, 2 \mathrm{H}), 3.76(\mathrm{~s}$, $3 \mathrm{H}), 3.40-3.34(\mathrm{~m}, 4 \mathrm{H}), 2.56(\mathrm{t}, J=7.2 \mathrm{~Hz}, 2 \mathrm{H}), 2.28(\mathrm{~s}, 4 \mathrm{H}), 2.11(\mathrm{~s}, 3 \mathrm{H}), 1.79(\mathrm{~s}, 3 \mathrm{H}) .{ }^{13} \mathrm{C} \mathrm{NMR}(75 \mathrm{MHz}$, $\left.\mathrm{CDCl}_{3}\right): \delta 173.35,173.07,163.67,155.19,153.53,144.20,134.36,129.83,129.58(2 \mathrm{C}), 123.01,122.03$, $116.85,115.57(2 \mathrm{C}), 106.33,70.12,61.03,40.95,35.22,34.94,34.65,22.62,16.06,11.54$. ESI-HRMS $(\mathrm{m} / \mathrm{z})$ calcd for $\mathrm{C}_{25} \mathrm{H}_{30} \mathrm{NO}_{6}{ }^{+}[\mathrm{M}+\mathrm{H}]^{+}: 440.20676$, found: 440.20621 .

\subsection{6 (E)-N-butyl-6-(4-hydroxy-6-methoxy-7-methyl-3-oxo-1,3-dihydroisobenzofuran-5-yl)-4-methylhex-4- enamide (B1)}

White powder; yield 58\%; m.p. $76-78^{\circ} \mathrm{C} .{ }^{1} \mathrm{H}$ NMR $\left(300 \mathrm{MHz}, \mathrm{CDCl}_{3}, \mathrm{ppm}\right) \delta 7.70(\mathrm{~s}, 1 \mathrm{H}), 5.46(\mathrm{brs}, 1 \mathrm{H}), 5.28$ $(\mathrm{t}, J=7.2 \mathrm{~Hz}, 1 \mathrm{H}), 5.22(\mathrm{~s}, 2 \mathrm{H}), 3.79(\mathrm{~s}, 3 \mathrm{H}), 3.41(\mathrm{~d}, J=6.9 \mathrm{~Hz}, 2 \mathrm{H}), 3.20(\mathrm{dd}, J=12.6,6.0 \mathrm{~Hz}, 2 \mathrm{H}), 2.35-$ $2.23(\mathrm{~m}, 4 \mathrm{H}), 2.17(\mathrm{~s}, 3 \mathrm{H}), 1.83(\mathrm{~s}, 3 \mathrm{H}), 1.47-1.25(\mathrm{~m}, 4 \mathrm{H}), 0.91(\mathrm{t}, J=7.2 \mathrm{~Hz}, 3 \mathrm{H}) .{ }^{13} \mathrm{C} \mathrm{NMR}(75 \mathrm{MHz}$, $\left.\mathrm{CDCl}_{3}\right): \delta 172.93,172.56,163.69,153.62,144.03,134.72,122.80,122.10,116.79,106.37,70.07,61.02$, $39.18,35.33,35.18,31.68,22.62,20.04,16.13,13.72,11.57$. ESI-HRMS $(\mathrm{m} / \mathrm{z})$ calcd for $\mathrm{C}_{21} \mathrm{H}_{30} \mathrm{NO}_{5}{ }^{+}$ $[\mathrm{M}+\mathrm{H}]^{+}: 376.21185$, found: 376.21127 .

\subsection{7 (E)-6-(4-hydroxy-6-methoxy-7-methyl-3-oxo-1,3-dihydroisobenzofuran-5-yl)-4-methyl-N-pentylhex-4- enamide (B2)}

White powder; yield $65 \%$; m.p. $108-110^{\circ} \mathrm{C} .{ }^{1} \mathrm{H} \mathrm{NMR}\left(300 \mathrm{MHz}, \mathrm{CDCl}_{3}, \mathrm{ppm}\right) \delta 7.70(\mathrm{~s}, 1 \mathrm{H}), 5.47(\mathrm{brs}, 1 \mathrm{H})$, $5.27(\mathrm{t}, J=6.9 \mathrm{~Hz}, 1 \mathrm{H}), 5.22(\mathrm{~s}, 2 \mathrm{H}), 3.78(\mathrm{~s}, 3 \mathrm{H}), 3.41(\mathrm{~d}, J=6.9 \mathrm{~Hz}, 2 \mathrm{H}), 3.22-3.15(\mathrm{~m}, 2 \mathrm{H}), 2.36-2.26(\mathrm{~m}$, $4 \mathrm{H}), 2.17(\mathrm{~s}, 3 \mathrm{H}), 1.83(\mathrm{~s}, 3 \mathrm{H}), 1.48-1.39(\mathrm{~m}, 2 \mathrm{H}), 1.35-1.24(\mathrm{~m}, 4 \mathrm{H}), 0.90(\mathrm{t}, J=6.6 \mathrm{~Hz}, 3 \mathrm{H}) .{ }^{13} \mathrm{C}$ NMR $(75$ $\left.\mathrm{MHz}, \mathrm{CDCl}_{3}\right): \delta 172.93,172.51,163.68,153.63,144.02,134.74,122.79,122.10,116.79,106.38,70.06$, 
$61.02,39.45,35.33,35.21,29.31,29.05,22.62,22.33,16.14,13.97,11.57$. ESI-HRMS $(\mathrm{m} / \mathrm{z}) \mathrm{calcd}$ for $\mathrm{C}_{22} \mathrm{H}_{32} \mathrm{NO}_{5}{ }^{+}[\mathrm{M}+\mathrm{H}]^{+}: 390.22750$, found: 390.22690 .

\subsection{8 (E)-N-hexyl-6-(4-hydroxy-6-methoxy-7-methyl-3-oxo-1,3-dihydroisobenzofuran-5-yl)-4-methylhex-4- enamide (B3)}

White powder; yield $63 \%$; m.p. $106-108^{\circ} \mathrm{C} .{ }^{1} \mathrm{H} \mathrm{NMR}\left(300 \mathrm{MHz}, \mathrm{CDCl}_{3}, \mathrm{ppm}\right) \delta 7.70(\mathrm{~s}, 1 \mathrm{H}), 5.47$ (brs, $\left.1 \mathrm{H}\right)$, $5.27(\mathrm{t}, J=6.9 \mathrm{~Hz}, 1 \mathrm{H}), 5.22(\mathrm{~s}, 2 \mathrm{H}), 3.79(\mathrm{~s}, 3 \mathrm{H}), 3.41(\mathrm{~d}, J=6.9 \mathrm{~Hz}, 2 \mathrm{H}), 3.22-3.15(\mathrm{~m}, 2 \mathrm{H}), 2.35-2.24(\mathrm{~m}$, $4 \mathrm{H}), 2.17(\mathrm{~s}, 3 \mathrm{H}), 1.83(\mathrm{~s}, 3 \mathrm{H}), 1.47-1.37(\mathrm{~m}, 2 \mathrm{H}), 1.28(\mathrm{~s}, 6 \mathrm{H}), 0.90(\mathrm{t}, J=6.3 \mathrm{~Hz}, 3 \mathrm{H}) .{ }^{13} \mathrm{C} \mathrm{NMR}(75 \mathrm{MHz}$, $\left.\mathrm{CDCl}_{3}\right): \delta 172.92,172.52,163.68,153.63,144.02,134.74,122.80,122.10,116.78,106.38,70.06,61.02$, $39.49,35.34,35.21,31.47,29.59,26.58,22.62,22.55,16.14,14.01,11.57$. ESI-HRMS $(\mathrm{m} / \mathrm{z}) \mathrm{calcd}$ for $\mathrm{C}_{23} \mathrm{H}_{34} \mathrm{NO}_{5}{ }^{+}[\mathrm{M}+\mathrm{H}]^{+}:$404.24315, found: 404.24274 .

4.1.9

Methyl (E)-(6-(4-hydroxy-6-methoxy-7-methyl-3-oxo-1,3-dihydroisobenzofuran-5-yl)-4-methylhex-4enoyl)glycinate (C1)

White powder; yield 70\%; m.p. 98-100 ${ }^{\circ} \mathrm{C} .{ }^{1} \mathrm{H} \mathrm{NMR}\left(300 \mathrm{MHz}, \mathrm{CDCl}_{3}, \mathrm{ppm}\right) \delta 7.71$ (brs, $\left.1 \mathrm{H}\right), 6.01$ (brs, $\left.1 \mathrm{H}\right)$, $5.29(\mathrm{t}, J=6.9 \mathrm{~Hz}, 1 \mathrm{H}), 5.22(\mathrm{~s}, 2 \mathrm{H}), 3.99(\mathrm{~d}, J=5.1 \mathrm{~Hz}, 2 \mathrm{H}), 3.78(\mathrm{~s}, 3 \mathrm{H}), 3.76(\mathrm{~s}, 3 \mathrm{H}), 3.41(\mathrm{~d}, J=6.9 \mathrm{~Hz}$, 2H), $2.35(\mathrm{~s}, 4 \mathrm{H}), 2.16(\mathrm{~s}, 3 \mathrm{H}), 1.83(\mathrm{~s}, 3 \mathrm{H}) .{ }^{13} \mathrm{C} \mathrm{NMR}\left(75 \mathrm{MHz}, \mathrm{CDCl}_{3}\right): \delta 172.90,172.82,170.48,163.66$, $153.61,144.05,134.39,123.08,122.09,116.77,106.39,70.05,61.02,52.34,41.13,35.05,34.80,22.62$, 16.11, 11.56. ESI-HRMS $(\mathrm{m} / \mathrm{z})$ calcd for $\mathrm{C}_{20} \mathrm{H}_{26} \mathrm{NO}_{7}{ }^{+}[\mathrm{M}+\mathrm{H}]^{+}: 392.17038$, found: 392.17004 .

4.1.10

methyl (E)-(6-(4-hydroxy-6-methoxy-7-methyl-3-oxo-1,3-dihydroisobenzofuran-5-yl)-4-methylhex-4enoyl)phenylalaninate (C2)

White powder; yield $67 \%$; m.p. $82-84^{\circ} \mathrm{C} .{ }^{1} \mathrm{H}$ NMR $\left(300 \mathrm{MHz}, \mathrm{CDCl}_{3}, \mathrm{ppm}\right) \delta 7.69(\mathrm{~s}, 1 \mathrm{H}), 7.32-7.29(\mathrm{~m}, 1 \mathrm{H})$, 7.28-7.24 (m, 2H), $7.07(\mathrm{dd}, J=7.8 \mathrm{~Hz}, 2.1 \mathrm{~Hz}, 2 \mathrm{H}), 5.92(\mathrm{~d}, J=8.7 \mathrm{~Hz}, 1 \mathrm{H}), 5.26(\mathrm{t}, J=6.9 \mathrm{~Hz}, 1 \mathrm{H}), 5.17(\mathrm{~s}$, $2 \mathrm{H}), 4.90-4.83(\mathrm{~m}, 1 \mathrm{H}), 3.78(\mathrm{~s}, 3 \mathrm{H}), 3.72(\mathrm{~s}, 3 \mathrm{H}), 3.40(\mathrm{~d}, J=6.9 \mathrm{~Hz}, 2 \mathrm{H}), 3.05(\mathrm{t}, J=5.4 \mathrm{~Hz}, 2 \mathrm{H}), 2.30(\mathrm{~s}$, 4H), 2.15 (s, 3H), 1.81 (s, 3H). $\left.{ }^{13} \mathrm{C} \mathrm{NMR} \mathrm{(75} \mathrm{MHz,} \mathrm{CDCl}_{3}\right)$ : $\delta$ 172.90, 172.09 (2C), 163.66, 153.60, 144.06, 135.90, 134.38, 129.20 (2C), 128.54 (2C), 127.09, 122.83, 122.05, 116.73, 106.38, 70.02, 61.01, 53.00, $52.28,37.95,35.00,34.91,22.61,16.15,11.57$. ESI-HRMS $(\mathrm{m} / \mathrm{z})$ calcd for $\mathrm{C}_{27} \mathrm{H}_{32} \mathrm{NO}_{7}{ }^{+}$ $[\mathrm{M}+\mathrm{H}]^{+}:$: 482.21733, found: 482.21692 .

4.1.11 (E)-N-(2-(dimethylamino)ethyl)-6-(4-hydroxy-6-methoxy-7-methyl-3-oxo-1,3-dihydroisobenzofuran-5yl)-4-methylhex-4-enamide (D1) 
White powder; yield 79\%; m.p. 76-78 ${ }^{\circ} \mathrm{C} .{ }^{1} \mathrm{H}$ NMR $\left(300 \mathrm{MHz}, \mathrm{CDCl}_{3}, \mathrm{ppm}\right) \delta 7.44$ (brs, $\left.1 \mathrm{H}\right), 5.30-5.24(\mathrm{~m}$, $1 \mathrm{H}), 5.21$ (s, 2H), $3.78(\mathrm{~s}, 3 \mathrm{H}), 3.57$ (dd, $J=10.2 \mathrm{~Hz}, 5.3 \mathrm{~Hz}, 2 \mathrm{H}), 3.40(\mathrm{~d}, J=6.7 \mathrm{~Hz}, 2 \mathrm{H}), 3.01$ (t, $J=5.1 \mathrm{~Hz}$, 2H), 2.72 (s, 6H), 2.36 (brs, 4H), $2.16(\mathrm{~s}, 3 \mathrm{H}), 1.83(\mathrm{~s}, 3 \mathrm{H}) .{ }^{13} \mathrm{C} \mathrm{NMR}\left(75 \mathrm{MHz}, \mathrm{CDCl}_{3}\right) \delta 173.55,172.82$, 163.62, 153.82, 144.16, 134.66, 122.73, 122.32, 116.62, 106.44, 69.95, 61.05, 58.11, 44.05(2C), 35.13, $35.11,34.98,22.68,16.24,11.55$. ESI-HRMS $(\mathrm{m} / \mathrm{z})$ calcd for $\mathrm{C}_{21} \mathrm{H}_{31} \mathrm{~N}_{2} \mathrm{O}_{5}{ }^{+}$

$[\mathrm{M}+\mathrm{H}]^{+}: 391.22275$, found: 391.22235 .

\subsubsection{2 (E)-N-(2-(diethylamino)ethyl)-6-(4-hydroxy-6-methoxy-7-methyl-3-oxo-1,3-dihydroisobenzofuran-5- yl)-4-methylhex-4-enamide (D2)}

White powder; yield 73\%; m.p. $60-62^{\circ} \mathrm{C} .{ }^{1} \mathrm{H}$ NMR $\left(300 \mathrm{MHz}, \mathrm{CDCl}_{3}\right) \delta 6.76(\mathrm{brs}, 1 \mathrm{H}), 5.26(\mathrm{t}, J=6.5 \mathrm{~Hz}, 1 \mathrm{H})$, $5.21(\mathrm{~s}, 2 \mathrm{H}), 3.78(\mathrm{~s}, 3 \mathrm{H}), 3.40(\mathrm{~d}, J=6.9 \mathrm{~Hz}, 4 \mathrm{H}), 2.74(\mathrm{~d}, J=7.1 \mathrm{~Hz}, 6 \mathrm{H}), 2.32(\mathrm{~s}, 4 \mathrm{H}), 2.16(\mathrm{~s}, 3 \mathrm{H}), 1.83(\mathrm{~s}$, 3H), $1.13(\mathrm{t}, J=7.1 \mathrm{~Hz}, 6 \mathrm{H}) .{ }^{13} \mathrm{C} \mathrm{NMR}\left(75 \mathrm{MHz}, \mathrm{CDCl}_{3}\right)$ : $\delta$ 172.97, 172.78, 163.60, 154.61, 144.11, 134.53, $123.06,122.37,116.04,106.41,69.89,61.01,51.62,46.75$ (2C), 36.62, 35.28 (2C), 22.74, 16.21, 11.54, $11.18(2 \mathrm{C})$. ESI-HRMS ( $\mathrm{m} / \mathrm{z})$ calcd for $\mathrm{C}_{23} \mathrm{H}_{35} \mathrm{~N}_{2} \mathrm{O}_{5}{ }^{+}[\mathrm{M}+\mathrm{H}]^{+}: 419.25405$, found: 419.25369 .

\subsubsection{3 (E)-N-(2-(ethyl(isopropyl)amino)ethyl)-6-(4-hydroxy-6-methoxy-7-methyl-3-oxo-1,3-} dihydroisobenzofuran-5-yl)-4-methylhex-4-enamide (D3)

White powder; yield $66 \%$; m.p. $58-60^{\circ} \mathrm{C} .{ }^{1} \mathrm{H}$ NMR $\left(300 \mathrm{MHz}, \mathrm{CDCl}_{3}\right) \delta 6.14$ (brs, $\left.1 \mathrm{H}\right), 5.25(\mathrm{t}, J=5.8 \mathrm{~Hz}, 1 \mathrm{H})$, $5.21(\mathrm{~s}, 2 \mathrm{H}), 3.77(\mathrm{~s}, 3 \mathrm{H}), 3.40(\mathrm{~d}, J=6.8 \mathrm{~Hz}, 2 \mathrm{H}), 3.21(\mathrm{~d}, J=5.3 \mathrm{~Hz}, 2 \mathrm{H}), 3.02(\mathrm{t}, J=6.0 \mathrm{~Hz}, 2 \mathrm{H}), 2.57$ (brs, 2H), $2.41-2.19(\mathrm{~m}, 5 \mathrm{H}), 2.16(\mathrm{~s}, 3 \mathrm{H}), 1.82(\mathrm{~s}, 3 \mathrm{H}), 1.02(\mathrm{~d}, J=6.4 \mathrm{~Hz}, 12 \mathrm{H}) .{ }^{13} \mathrm{C} \mathrm{NMR}\left(75 \mathrm{MHz}, \mathrm{CDCl}_{3}\right): \delta$ 172.94, 172.38, 163.69, 153.70, 144.01, 134.66, 122.50, 122.18, 116.68, 106.36, 70.04, 61.02 (2C), 47.68, $43.01,37.90,35.41,35.37,22.62,20.78(2 \mathrm{C}), 16.21(2 \mathrm{C}), 11.57$. ESI-HRMS ( $\mathrm{m} / \mathrm{z})$ calcd for $\mathrm{C}_{25} \mathrm{H}_{39} \mathrm{~N}_{2} \mathrm{O}_{5}{ }^{+}$ $[\mathrm{M}+\mathrm{H}]^{+}:$447.28535, found: 447.28503 .

\subsubsection{4 (E)-N-(2-acetamidoethyl)-6-(4-hydroxy-6-methoxy-7-methyl-3-oxo-1,3-dihydroisobenzofuran-5-yl)-4- methylhex-4-enamide (D4)}

White powder; yield 72\%; m.p. 98-100 ${ }^{\circ} \mathrm{C} .{ }^{1} \mathrm{H}$ NMR $\left(300 \mathrm{MHz}, \mathrm{CDCl}_{3}\right) \delta 7.71(\mathrm{~s}, 1 \mathrm{H}), 6.26(\mathrm{~d}, J=23.9 \mathrm{~Hz}$, 2H), $5.27(\mathrm{dd}, \mathrm{J}=15.0,8.2 \mathrm{~Hz}, 1 \mathrm{H}), 5.22(\mathrm{~s}, 2 \mathrm{H}), 3.78(\mathrm{~s}, 3 \mathrm{H}), 3.41(\mathrm{~d}, J=6.9 \mathrm{~Hz}, 2 \mathrm{H}), 3.32(\mathrm{t}, J=2.4 \mathrm{~Hz}$, 4H), 2.31 (s, 3H), $2.17(\mathrm{~s}, 2 \mathrm{H}), 1.98(\mathrm{~s}, 2 \mathrm{H}), 1.82(\mathrm{~s}, 3 \mathrm{H}), 1.66(\mathrm{~s}, 3 \mathrm{H}) .{ }^{13} \mathrm{C} \mathrm{NMR}\left(75 \mathrm{MHz}, \mathrm{CDCl}_{3}\right) \delta 174.05$, 172.92, 171.37, 163.60, 153.57, 144.18, 134.46, 122.92, 122.07, 116.84, 106.44, 70.09, 61.04, 40.31, $40.04,35.22,35.00,23.18,22.64,16.13,11.58$. ESI-HRMS $(\mathrm{m} / \mathrm{z})$ calcd for $\mathrm{C}_{21} \mathrm{H}_{29} \mathrm{~N}_{2} \mathrm{O}_{6}{ }^{+}$ $[\mathrm{M}+\mathrm{H}]^{+}:$: 405.20201, found: 405.20178 .

4.1.15 (E)-6-(4-hydroxy-6-methoxy-7-methyl-3-oxo-1,3-dihydroisobenzofuran-5-yl)-4-methyl-N-(2-(piperidin1-yl)ethyl)hex-4-enamide (E1) 
White powder; yield 65\%; m.p. 122-124 ${ }^{\circ} \mathrm{C} .{ }^{1} \mathrm{H}$ NMR $\left(300 \mathrm{MHz}, \mathrm{CDCl}_{3}\right) \delta 6.49(\mathrm{~s}, 1 \mathrm{H}), 5.27(\mathrm{t}, J=6.5 \mathrm{~Hz}$, $1 \mathrm{H}), 5.18(\mathrm{~s}, 2 \mathrm{H}), 3.78(\mathrm{~s}, 3 \mathrm{H}), 3.46-3.29(\mathrm{~m}, 4 \mathrm{H}), 2.71-2.41(\mathrm{~m}, 6 \mathrm{H}), 2.32(\mathrm{~s}, 4 \mathrm{H}), 2.15(\mathrm{~s}, 3 \mathrm{H}), 1.83(\mathrm{~s}$, $3 \mathrm{H}), 1.64(\mathrm{dt}, J=10.9,5.6 \mathrm{~Hz}, 4 \mathrm{H}), 1.48(\mathrm{~d}, J=5.2 \mathrm{~Hz}, 2 \mathrm{H}) .{ }^{13} \mathrm{C} \mathrm{NMR}\left(75 \mathrm{MHz}, \mathrm{CDCl}_{3}\right) \delta 173.01,172.83$, $163.45,156.03,144.27,134.21,123.96,122.60,114.97,106.41,69.64,60.99,57.20,54.75(2 \mathrm{C}), 36.19$, $35.24,34.98,25.45(2 \mathrm{C}), 23.94,22.96,15.97,11.48$. ESI-HRMS $(\mathrm{m} / \mathrm{z})$ calcd for $\mathrm{C}_{24} \mathrm{H}_{35} \mathrm{~N}_{2} \mathrm{O}_{5}{ }^{+}$ $[\mathrm{M}+\mathrm{H}]^{+}: 431.25045$, found: 431.25381 .

\subsubsection{6 (E)-6-(4-hydroxy-6-methoxy-7-methyl-3-oxo-1,3-dihydroisobenzofuran-5-yl)-4-methyl-N-(2-(pyrrolidin-} 1-yl)ethyl)hex-4-enamide (E2)

White powder; yield 59\%; m.p. $130-132{ }^{\circ} \mathrm{C} .{ }^{1} \mathrm{H} \mathrm{NMR}\left(300 \mathrm{MHz}, \mathrm{CDCl}_{3}\right) \delta 6.69$ (brs, $\left.1 \mathrm{H}\right), 5.27(\mathrm{t}, \mathrm{J}=6.9 \mathrm{~Hz}$, 1H), 5.18 (s, 2H), $3.80(\mathrm{~s}, 3 \mathrm{H}), 3.41$ (dd, $J=11.7 \mathrm{~Hz}, 5.4 \mathrm{~Hz}, 4 \mathrm{H}), 2.91-2.71(\mathrm{~m}, 6 \mathrm{H}), 2.34(\mathrm{~s}, 4 \mathrm{H}), 2.15(\mathrm{~s}$, $3 \mathrm{H}), 1.93-1.85(\mathrm{~m}, 4 \mathrm{H}), 1.83(\mathrm{~s}, 3 \mathrm{H}) .{ }^{13} \mathrm{C}$ NMR $\left(75 \mathrm{MHz}, \mathrm{CDCl}_{3}\right) \delta 173.07(2 \mathrm{C}), 163.40,156.58,144.34$, $134.18,124.39,122.74,114.62,106.47,69.55,60.99,54.98,54.48(2 \mathrm{C}), 37.76,35.22,34.88,23.37(2 \mathrm{C})$, 23.00, 15.99, 11.46. ESI-HRMS $(\mathrm{m} / \mathrm{z})$ calcd for $\mathrm{C}_{23} \mathrm{H}_{33} \mathrm{~N}_{2} \mathrm{O}_{5}{ }^{+}[\mathrm{M}+\mathrm{H}]^{+}: 417.23840$, found: 417.23795 .

4.1.17

(E)-N-(2-(1H-indol-3-yl)ethyl)-6-(4-hydroxy-6-methoxy-7-methyl-3-oxo-1,3-dihydroisobenzofuran-5-yl)-4methylhex-4-enamide (E3)

White powder; yield 51\%; m.p. $116-118^{\circ} \mathrm{C} .{ }^{1} \mathrm{H} \mathrm{NMR}\left(300 \mathrm{MHz}, \mathrm{CDCl}_{3}\right) \delta 8.39(\mathrm{~s}, 1 \mathrm{H}), 7.69(\mathrm{~s}, 1 \mathrm{H}), 7.54$ (d, J $=7.7 \mathrm{~Hz}, 1 \mathrm{H}), 7.37(\mathrm{~d}, J=8.0 \mathrm{~Hz}, 1 \mathrm{H}), 7.25-7.16(\mathrm{~m}, 1 \mathrm{H}), 7.15-7.05(\mathrm{~m}, 1 \mathrm{H}), 6.98(\mathrm{~d}, J=2.1 \mathrm{~Hz}, 1 \mathrm{H})$, $5.67(\mathrm{t}, J=5.4 \mathrm{~Hz}, 1 \mathrm{H}), 5.25(\mathrm{t}, J=6.9 \mathrm{~Hz}, 1 \mathrm{H}), 5.00(\mathrm{~s}, 2 \mathrm{H}), 3.77(\mathrm{~d}, J=6.3 \mathrm{~Hz}, 3 \mathrm{H}), 3.52(\mathrm{dd}, J=12.9,6.8$ $\mathrm{Hz}, 2 \mathrm{H}), 3.38(\mathrm{~d}, J=6.9 \mathrm{~Hz}, 2 \mathrm{H}), 2.82(\mathrm{t}, J=6.9 \mathrm{~Hz}, 2 \mathrm{H}), 2.36-2.20(\mathrm{~m}, 4 \mathrm{H}), 2.09(\mathrm{~s}, 3 \mathrm{H}), 1.80(\mathrm{~s}, 3 \mathrm{H}) .{ }^{13} \mathrm{C}$ $\operatorname{NMR}\left(75 \mathrm{MHz}, \mathrm{CDCl}_{3}\right) \delta 173.00,172.87,163.59,153.46,144.21,136.41,134.51,127.27,122.83,122.16$, $122.00,121.90,119.19,118.54,116.83,112.62,111.36,106.30,70.04,61.03,39.78,35.28,35.04,25.27$, $22.62,16.12,11.50$. ESI-HRMS $(\mathrm{m} / \mathrm{z})$ calcd for $\mathrm{C}_{27} \mathrm{H}_{31} \mathrm{~N}_{2} \mathrm{O}_{5}{ }^{+}[\mathrm{M}+\mathrm{H}]^{+}: 463.22275$, found: 463.22253 .

\subsubsection{8 (E)-6-(6-(4-benzylpiperazin-1-yl)-3-methyl-6-oxohex-2-en-1-yl)-7-hydroxy-5-methoxy-4- methylisobenzofuran-1(3H)-one (E4)}

White powder; yield $73 \%$; m.p. $121-123^{\circ} \mathrm{C} .{ }^{1} \mathrm{H}$ NMR $\left(300 \mathrm{MHz}, \mathrm{CDCl}_{3}\right) \delta 7.36-7.29(\mathrm{~m}, 4 \mathrm{H}), 7.25(\mathrm{dd}, J=$ 8.8, 3.8 Hz, 1H), $5.27-5.22(\mathrm{~m}, 1 \mathrm{H}), 5.20(\mathrm{~s}, 2 \mathrm{H}), 3.77(\mathrm{~s}, 3 \mathrm{H}), 3.59(\mathrm{t}, J=4.8 \mathrm{~Hz}, 2 \mathrm{H}), 3.51(\mathrm{~s}, 2 \mathrm{H}), 3.44(\mathrm{t}$, $J=4.8 \mathrm{~Hz}, 2 \mathrm{H}), 3.39(\mathrm{~d}, J=6.8 \mathrm{~Hz}, 2 \mathrm{H}), 2.50-2.35(\mathrm{~m}, 6 \mathrm{H}), 2.32-2.25(\mathrm{~m}, 2 \mathrm{H}), 2.15(\mathrm{~s}, 3 \mathrm{H}), 1.82(\mathrm{~s}, 3 \mathrm{H})$.

${ }^{13} \mathrm{C} \mathrm{NMR}\left(75 \mathrm{MHz}, \mathrm{CDCl}_{3}\right)$ : $\delta 172.88,171.18,163.65,153.57,144.07,137.47,134.77,129.15(2 \mathrm{C})$, $128.31(2 \mathrm{C}), 127.28,122.41,122.19,116.75,106.36,70.02,62.82,61.02,53.11,52.73,45.54,41.48,35.02$, $31.94,22.63,16.39,11.57$. ESI-HRMS $(m / z)$ calcd for $\mathrm{C}_{28} \mathrm{H}_{35} \mathrm{~N}_{2} \mathrm{O}_{5}{ }^{+}$

$[\mathrm{M}+\mathrm{H}]^{+}:$479.25405, found: 479.25369 . 


\subsubsection{9 (E)-N-(3-(1H-imidazol-1-yl)propyl)-6-(4-hydroxy-6-methoxy-7-methyl-3-oxo-1,3- dihydroisobenzofuran-5-yl)-4-methylhex-4-enamide(E5)}

White powder; yield 63\%; m.p. 116-118 C. ${ }^{1} \mathrm{H}$ NMR $\left(300 \mathrm{MHz} \mathrm{CDCl}_{3}\right) \delta 7.47(\mathrm{~s}, 1 \mathrm{H}), 6.99(\mathrm{~d}, \mathrm{~J}=38.6 \mathrm{~Hz}$, 2H), $5.69(\mathrm{~s}, 1 \mathrm{H}), 5.28(\mathrm{t}, J=11.6 \mathrm{~Hz}, 1 \mathrm{H}), 5.21(\mathrm{~s}, 2 \mathrm{H}), 3.95(\mathrm{t}, J=6.9 \mathrm{~Hz}, 2 \mathrm{H}), 3.77(\mathrm{~s}, 3 \mathrm{H}), 3.44$ (t, J = 16.4 $\mathrm{Hz}, 2 \mathrm{H}), 3.22$ (dd, J = 12.8, $6.4 \mathrm{~Hz}, 2 \mathrm{H}), 2.30$ (s, 4H), $2.15(\mathrm{~s}, 3 \mathrm{H}), 2.02-1.89(\mathrm{~m}, 2 \mathrm{H}), 1.83(\mathrm{~s}, 3 \mathrm{H}) .{ }^{13} \mathrm{C}$ $\operatorname{NMR}\left(75 \mathrm{MHz}_{,} \mathrm{CDCl}_{3}\right) \delta 173.15,172.89,163.61,153.60,144.17,134.57(2 \mathrm{C}), 132.34,122.90(2 \mathrm{C}), 122.12$, $116.84,106.44,70.05,61.04,44.61,36.58,35.16,34.91,31.24,22.67,16.18,11.57$. ESI-HRMS $(\mathrm{m} / \mathrm{z}) \mathrm{calcd}$ for $\mathrm{C}_{23} \mathrm{H}_{30} \mathrm{~N}_{3} \mathrm{O}_{5}{ }^{+}[\mathrm{M}+\mathrm{H}]^{+}:$428.21800, found: 428.21771.

\subsection{Materials needed for cell and animal experiments}

3-(4,5-Dimethylthiazol-2-yl)-2,5-diphenyl-2H-tetrazolium bromide (MTT) was purchased from SigmaAldrich Co. (St. Louis, MO, USA). HFF-1 cell (Human Foreskin Fibroblasts-1) was purchased from American Type Culture Collection (ATCC, Manassas, VA, USA). Toxoplasma gondii is a highly virulent Toxoplasma gondii RH strain, which was donated by the Zoonoses Research Center, Won Kwang University School of Medicine, South Korea. The experimental animals were provided by the Animal Experiment Center of Yanbian University (license number SCXK 2011-0007), and are raised in the animal laboratory of the School of Pharmacy, Yanbian University, the experimental conditions meet the national laboratory animal requirements.

\subsection{In vitro anti-T. gondii experiment}

The cytotoxicity and anti-T. gondii activity of the compounds were tested by the classic MTT method. HFF-1 cells what in the logarithmic growth phase was collected, and inoculated in a 96-well plate $\left(1 \times 10^{4}\right.$ cells per well), after $24 \mathrm{~h}$ of incubation, adding Toxoplasma gondii tachyzoites at a ratio of cells per well: Toxoplasma gondii $=1: 5$, continue to cultivate for $24 \mathrm{~h}$, and then added different concentrations of test drugs $(10-1000 \mu \mathrm{M})$, in addition, spiramycin and DMSO were used as a positive control and negative control respectively, the final concentration of DMSO solvent did not exceed $0.1 \%$. After $24 \mathrm{~h}$ of incubation, $15 \mu \mathrm{L}$ of MTT solution $(0.5 \mathrm{mg} / \mathrm{mL})$ was added to each well, the OD value (absorbance) was read on a microplate reader at a wavelength of $492 \mathrm{~nm}$. The cytotoxicity of the tested drugs was determined under the same experimental conditions, except that the cells were not infected with Toxoplasma gondii, and the other operating methods were the same. After determining the OD value, the $\mathrm{IC}_{50}$ of each group of cells and the selectivity index $(\mathrm{SI})$ were calculated.

\subsection{In vivo anti-T. gondii experiment}

Thirty female KM mice were used for in vivo experiments. Six mice were randomly selected as the normal group without any treatment. The remaining 24 mice were used to establish an acute Toxoplasma infection animal model (Toxoplasma gondii was injected intraperitoneally in mice ( $2 \times 10^{3} /$ mouse)), which was then randomly divided into four groups (infected but not treatment group, Spiramycin group, MPA 
group, E5 group), each group has six animals. Four hours after infection, each test compound was given to mice by gavage at $100 \mathrm{mg} / \mathrm{kg}$ once a day for four consecutive days. The untreated group was given the same dose of normal saline. On the 5th day, the mice's eye blood was collected and sacrificed by cervical dislocation. Their abdominal cavity was rinsed with sterile physiological saline to collect the parasites/tachyzoites. Those were counted under an optical microscope (BDS200 inverted microscope) to calculate the inhibitory rate of the drug on Toxoplasma gondii. At the same time, the liver and spleen were dissected, and the liver and spleen index, serum alanine aminotransferase (ALT), aspartate aminotransferase AST, liver homogenate glutathione $\mathrm{GSH}$, and malondialdehyde MDA were determined. Moreover record the weight change of mice during the administration period.

\subsubsection{The liver and spleen index assay}

After the mice of each group were sacrificed by neck dissection, they were dissected, the liver and kidney of the mice were separated, and the weight of the liver and spleen of each mouse was weighed and recorded, and then the liver and spleen index was obtained. The dissected liver and spleen were stored at low temperature, and the unused internal organs were temporarily stored in a refrigerator at $-80^{\circ} \mathrm{C}$.

Liver (spleen) index (\%) = [wet weight of liver/spleen (g) / body weight of mice $(\mathrm{g})] \times 100 \%$

\subsubsection{Determination of ALT and AST in serum}

The determination of AST and ALT in serum is based on Lai's method. An appropriate amount of serum was mixed with 5 times the amount of ALT or AST matrix buffer, then it was placed at $37^{\circ} \mathrm{C}$ for $30 \mathrm{~min}$, and $1 \mathrm{mmol} / \mathrm{L}$ 2,4-dinitrophenylhydrazine solution equal in volume was added to the matrix buffer and mixed well, after $20 \mathrm{~min}, 0.4 \mathrm{~mol} / \mathrm{L}$ sodium hydroxide solution was added and placed at room temperature for $5 \mathrm{~min}$. Adjusting the zero with distilled water at a wavelength of $505 \mathrm{~nm}$, the absorbance of each sample was read and calculated, and obtained the concentration of ALT and AST in the serum $(\mathrm{U} / \mathrm{L})$ through the standard curve ${ }^{[52]}$.

ALT matrix buffer: $1.79 \mathrm{~g}$ of DL-alanine and $29.2 \mathrm{mg}$ of a-ketoglutarate were accurately weighed, and dissolved using an appropriate amount of $0.1 \mathrm{~mol} / \mathrm{L}$ phosphate buffer. After that, $1 \mathrm{~mol} / \mathrm{L}$ of sodium hydroxide solution was added to adjust the $\mathrm{pH}$ to 7.4. Finally, additional phosphate buffer was added to adjust the volume to $100 \mathrm{ml}$ to obtain the ALT matrix buffer (stored at $4^{\circ} \mathrm{C}$ ).

AST matrix buffer: $24.2 \mathrm{mg}$ a-ketoglutarate and $2.66 \mathrm{~g}$ DL-aspartic acid were accurately weighed, and dissolved using appropriate amount of $0.1 \mathrm{mo} / \mathrm{L}$ phosphate buffer. After that, $1 \mathrm{~mol} / \mathrm{L}$ of sodium hydroxide solution was added to adjust the $\mathrm{pH}$ to 7.4. Finally, Finally, additional phosphate buffer was added to adjust the volume to $100 \mathrm{ml}$ to obtain the AST matrix buffer (stored at $4^{\circ} \mathrm{C}$ ).

\subsubsection{Determination of GSH and MDA in liver homogenate}

Preparation of liver homogenate: A certain amount of liver tissue was washed using pre-cooled physiological saline, and then an electric homogeniser was used to prepare a $20 \%$ tissue homogenate in 
$0.85 \%$ normal saline after drying. Followed by centrifugation ( $4000 \mathrm{rpm}, 10 \mathrm{~min}$ ), the supernatant was taken as a liquid reserve. The whole process should be carried out at low temperature as much as possible.

Protein content determination: The protein content of each group of mouse liver homogenate was tested according to the BCA protein concentration determination kit (Shanghai Biyuntian Biotechnology Co., Ltd.).

GSH determination: An appropriate amount of liver homogenate supernatant was mixed according to the supernatant: $20 \%$ trichloroacetic acid $=2: 1$, followed by centrifugation ( $4000 \mathrm{rpm}, 10 \mathrm{~min}$ ). Subsequently, the prepared $0.3 \mathrm{~mol} / \mathrm{L}$ disodium hydrogen phosphate buffer and $0.04 \%$ DTNB reagent were added in sequence and mixed thoroughly, and then the absorbance value was measured at $412 \mathrm{~nm}$. In the experiment, the GSH standard curve was drawn with glutathione standard substance and the regression equation was obtained. Substituting the measured absorbance value of the experimental sample into the regression equation, the concentration of GSH in each sample solution can be calculated. Finally, the GSH content in the liver homogenate $(\mathrm{mg} / \mathrm{gprot})=$ the measured GSH concentration in the sample solution $(\mathrm{mg} / \mathrm{ml}) /$ the liver homogenate protein concentration $(\mathrm{gprot} / \mathrm{ml})^{[53]}$.

MDA determination: MDA is determined by the thiobarbituric acid method. A certain amount of liver homogenate supernatant was mixed with $0.5 \%$ thiobarbituric acid, and then it was boiled in a water bath for $1 \mathrm{~h}$, centrifuged after cooling (6000 rpm, $10 \mathrm{~min}$ ). Moreover the upper pink clear liquid was measured absorbance value at $532 \mathrm{~nm}$. In addition, 1,1,2,2-tetraethoxypropane was used as a standard sample to draw a standard curve, and the absorbance value of the experimental sample was substituted into the standard curve to obtain the MDA concentration of each sample solution. Finally, the MDA content in the liver homogenate $(\mu \mathrm{mol} / \mathrm{gprot})=$ the measured MDA concentration in the sample solution $(\mu \mathrm{mol} / \mathrm{ml}) /$ the liver homogenate protein concentration $(\mathrm{gprot} / \mathrm{ml})^{[54]}$.

\section{Declarations}

\section{Acknowledgements}

This work was supported by the National Natural Science Foundation of China (No.81960626) and the Higher Education Discipline Innovation Project (111 Project, D18012). Thanks for the language editing service provided by the Cactus Communications (Shanghai) Co., Ltd. for the manuscript.

\section{Declaration of competing interest}

The authors declare no confflict of interest.

\section{References}


1. Luder CG, Bohne W, Soldati D (2001) Toxoplasmosis: a persisting challenge. Trends Parasitol $17: 460-463$

2. Osunkalu VO, Akanmu SA, Ofomah NJ et al (2011) Seroprevalence of Toxoplasma gondii IgG antiody in HIV-infected patients at the Lagos University teaching hospital. HIV AIDS (AuckI) 3:101105

3. Lang C, Grob U, Luder CGK (2007) Subversion of innate and adaptative immuneresponses by Toxoplasma gondi. Parasitol Res 100:191-203

4. Innes EA (2010) A brief history and overview of Toxoplasma gondi. Zoonoses Public Hlth 57:1-7

5. Bianchi G. Lipids and phenols in table olives. Eur J Lipid Sci Technol 2003;105: 229 - 242

6. Schoondermark-van de Ven E, Vree T, Melchers W et al (1995) In vitroeffects of sulfadiazine and its metabolites alone and in combination with pyrimethamine on Toxoplasma gondii. Antimicrob Agents Ch 39:763-765

7. Borkowski PK, Brydak-Godowska J, Basiak W et al (2018) Adverse reactions in antifolate-treated toxoplasmic retinochoroiditis. Curr Trends Immunity Respiratory Infect 1108:37-48

8. Adeyemi OS, Murata Y, Sugi T et al (2017) Inorganic nanoparticles kill Toxoplasma gondii via changes in redox status and mitochondrial membrane potential. Int J Nanomed 12:1647-1661

9. Ramos-Casals M, Font $J$ (2005) Mycophenolate mofetil in patients with hepatitis C virus infection. Lupus 14:64-72

10. Chan TM, Li FK, Tang CS (2000) Efficacy of mycophenolate mofetil in patients with diffuse proliferative lupus nephritis. N Engl J Med 343:1156-1162

11. Schlitt HJ, Barkmann A, Boker KH (2001) Replacement of calcineurin inhibitors with mycophenolate mofetil in liver-transplant patients with renal dysfunction: a randomised controlled study. Lancet 357:587-591

12. Siebert A, Wysocka M, Krawczyk B et al (2018) Synthesis and antimicrobial activity of amino acid and peptide derivatives of mycophenolic acid. Eur J Med Chem 143:646-655

13. Yin YB, Wang YJ, Dang W et al (2016) Mycophenolic acid potently inhibits rotavirus infection with a high barrier to resistance development. Antivir Res 133:41-49

14. Tsolaki E, Eleftheriou P, Kartsev V et al (2018) Application of Docking Analysis in the Prediction and Biological Evaluation of the Lipoxygenase Inhibitory Action of Thiazolyl Derivativesof Mycophenolic Acid. Molecules 23:1621

15. Prejs M, Cholewinski G, Siebert A et al (2016) New conjugates of mycophenolic acid and their antiproliferative activity. J Asian Nat Prod Res 18:1057-1062

16. Castro-Elizalde KN, Hernández-Contreras P, Ramírez-Flores CJ (2018) Mycophenolic acid induces differentiation of Toxoplasma gondii RH strain tachyzoites into bradyzoites and formation of cystlike structure in vitro. Parasitol Res 117:563

17. Halle MB, Lee W, Yudhistira T et al. Mycophenolic Acid: Biogenesis, Compound Isolation, Biological Activity, and Historical Advances in Total Synthesis. Eur J Org Chem 2019;2315-2334 
18. Guo HY, Jin CM, Zhang HM et al (2019) Synthesis and Biological Evaluation of (+)-Usnic Acid Derivatives as Potential Anti-Toxoplasma gondii Agents. J Agric Food Chem 67:9630-9642

19. Zhang HJ, Zhang GR, Piao HR et al (2017) Synthesis and characterisation of celastrol derivatives as potential anticancer agents. J Enzym Inhib Med Chem 33:190-198

20. Zhang TY, Li C, Li YR et al (2016) Synthesis and Antimicrobial Evaluation of Aminoguanidine and 3amino-1,2,4-triazole Derivatives as Potential Antibacterial Agents. Lett Drug Des Dis 13(10):10631075

21. Figueiredo SAC, Salvador JAR, Cortés R, Cascante M (2017) Design, synthesis and biological evaluation of novel C-29 carbamate celastrol derivatives as potent and selective cytotoxic compounds. Eur J Med Chem 139:836-848

22. Voynikov Y, Valcheva V, Momekov G (2014) Theophylline-7acetic acid derivatives with amino acids as anti-tuberculosisagents. Bioorg Med Chem Lett 24:3043-3045

23. Pang L, Liu CY, Gong GH et al (2020) Synthesis, in vitro and in vivo biological evaluation of novel lappaconitine derivatives as potential anti-inflammatory agents. Acta Pharmaceutica Sinica B 10:628-645

24. Bian M, Zhen D, Shen QK et al (2021) Structurally modified glycyrrhetinic acid derivatives as antiinflammatory agents. Bioorg Chem 107:104598

25. Zhang HB, Shen QK, Wang H et al (2018) Synthesis and evaluation of novel arctigenin derivatives as potential anti-Toxoplasma gondii agents. Eur J Med Chem 158:414-427

26. Luan T, Jin CM, Jin C-M et al (2019) Synthesis and biological evaluation of ursolic acid derivatives bearing triazole moieties as potential anti-Toxoplasma gondii agents. J Enzym Inhib Med Ch $34: 761-772$

27. Drag ZM, Kulbacka J, Saczko J et al (2009) Esters of betulin and betulinic acid with amino acids have improved water solubility and are selectively cytotoxic toward cancer cells. Bioorg Med Chem Lett 19:4814-4817

28. Lin JC, Cherng JM, Hung MS et al (2008) Inhibitory effects of some derivatives of glycyrrhizic acid against Epstein-Barrvirus infection: structureeactivity relationships. Antivir Res 79:6-11

29. Schwarz S, Csuk R (2010) Synthesis and antitumour activity of glycyrrhetinic acid derivatives. Bioorg Med Chem Lett 18:7458-7474

30. Kortagere S, Mui E, McLeod R et al (2011) Rapid discovery of inhibitors of Toxoplasma gondii using hybrid structurebased computational approach. J Comput Aided Mol Des 25:403-411

31. Kadri D, Crater AK, Lee H et al (2014) The potential of quinoline derivatives for the treatment of toxoplasma gondii infection. Exp Parasitol 145:135-144

32. Fang YQ, Zhang HJ, Ren Y et al (2018) Synthesis and Evaluation of the Antidepressant Activity of Quinoxaline-2,3(1H,4H)-dione Derivatives. Lat Am J Pharm 37(1):170-181

33. Davies JR, Kane PD, Moody CJ et al (2005) Control of competing N-H insertion and Wolff rearrangement in dirhodium(II)-Catalyzed reactions of 3-indolyl diazoketoesters. Synthesis of a 
potential precursor to the marine 5-(3-indolyl)oxazole martefragin A. J Org Chem 70:5840-5851

34. Beckmann HSG, Nie F, Hagerman CE et al (2013) A strategy for the diversity-oriented synthesis of macrocyclic scaffolds using multidimensional coupling. Nat Chem 5:861-867

35. Agnieszka S, Magdalena W, Beata K et al (2018) Synthesis and antimicrobial activity of amino acid and peptide derivatives of mycophenolic acid. Eur J Med Chem 143:646-655

36. Chetan PS, Prashant SK (2018) Newer human inosine 5'-monophosphate dehydrogenase 2 (hIMPDH2) inhibitors as potential anticancer agents. J Enzym Inhib Med Ch 33:972-977

37. Deng H, Huang $X$, Jin CM et al (2020) Synthesis, in vitro and in vivo biological evaluation of dihydroartemisinin derivatives with potential anti-Toxoplasma gondii agents. Bioorg Chem 94:103467

38. Dubey JP (2009) History of the discovery of the life cycle of Toxoplasma gondii. Int J Parasitol 39:877-882

39. Mordue DG, Monroy F, Regina M et al (2001) Acute toxoplasmosis leads to lethal overproduction of the cytokines. J Immunol 167:4574

40. Ustun S, Aksoy U, Dagci H, Galip E (2004) Frequency of toxoplasmosis in patients with cirrhosis. World J Gastroenterol 10:452-454

41. Mordue DG, Monroy F, Regina ML, Dinarello CA, Sibley D (2001) Acute toxoplasmosis leadsto lethal overproduction of Th1 cytokines. J Immunol 167:4574-4584

42. Znalesniak E, Fu T, Salm F et al (2017) Transcriptional responses in the murine spleen after toxoplasma gondii infection: inflammasome and mucus-associated genes. Int J Mol Sci 18:1245

43. Cho CW, Han CJ, Rhee YK (2015) Cheonggukjang polysaccharides enhance immune activities and prevent cyclophosphamide-induced immunosuppression. In J Biol Macromol 72:519-525

44. Autier B, Dion S, Robert-Gangneux F (2018) The liver as an organ at risk for Toxoplasma transmission during transplantation: myth or reality? J Clin Pathol 71:763-766

45. Choi HJ, Yu ST, Lee KI et al (2014) 6-Trifluoromethyl-2-thiouracil possesses anti-Toxoplasma gondii effect in vitro and in vivo with low hepatotoxicity. Exp Parasitol 143:24-29

46. Elsheikha HM, El-Motayam MH, Abouel-Nour MF, Morsy AT (2009) Oxidative stress and immunesuppression in Toxoplasma gondii positive blood donors: implications for safe blood transfusion. $J$ Egypt Soc Parasitol 39:421-428

47. Smith GR, Shanley GR (2013) Computational modelling of the regulation of Insulin signaling by oxidative stress. BMC Syst Boil 7:41-60

48. Kikuchiueda T, Ubagai T, Ono Y (2013) Priming effects of tumor necrosis -a on production of reactive oxygen species during Toxoplasma gondii stimulation and receptor gene expression in differentiated HL-60 cells. J Infect Chemother 19:1053-1064

49. Yang J, Dong S, Zhu H, Jiang Q, Yang J (2013) Molecular and expression analysis of manganese superoxide dismutase (Mn-SOD) gene under temperature and starvation stress in rotifer Brachionus calyciflorus. Mol Biol Rep 40:2927-2937 
50. Ebisch IMW, Thomas CMG, Peters WHM, Braat DDM, SteegersTheunissen RPM (2007) The importance of folate, zinc and antioxidants in the pathogenesis and prevention of subfertility. Hum Reprod Update 13:163-174

51. Grotto D, Maria LS, Valentini J, Paniz C, Schitt G, Garcia SC (2009) Importance of the lipidperoxidation biomarkers and methodological aspects for malondialdehyde quantification. Quim Nova 32:169-174

52. Jiang JH, Jin CM, Kim YC et al (2008) Anti-toxoplasmosis effects of oleuropein isolated from fraxinus rhychophylla. Biol Pharm Bull 31:2273-2276

53. Reitman S, Frankel S (1957) A colorimetric method for the determination of serum glutamic oxalacetic and glutamic pyruvic transaminases. Am J Clin Pathol 28:56-63

54. Griffith OW (1980) Determination of glutathione and glutathione disulfide using glutathione reductase and 2-vinylpyridine. Anal Biochem 106:207-212

\section{Tables}

Due to technical limitations, table 1-2 is only available as a download in the Supplemental Files section.

\section{Figures}

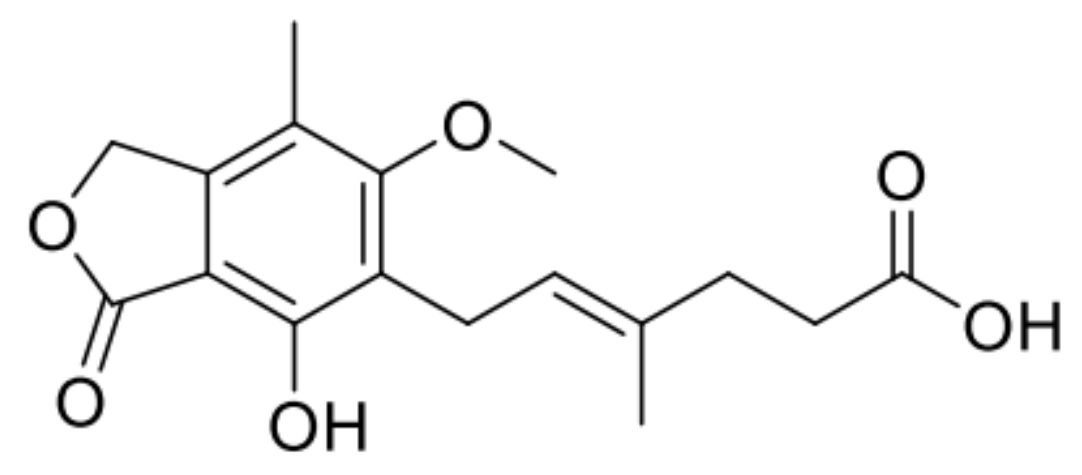

\section{mycophenolic acid}

\section{Figure 1}

The structure of mycophenolic acid. 


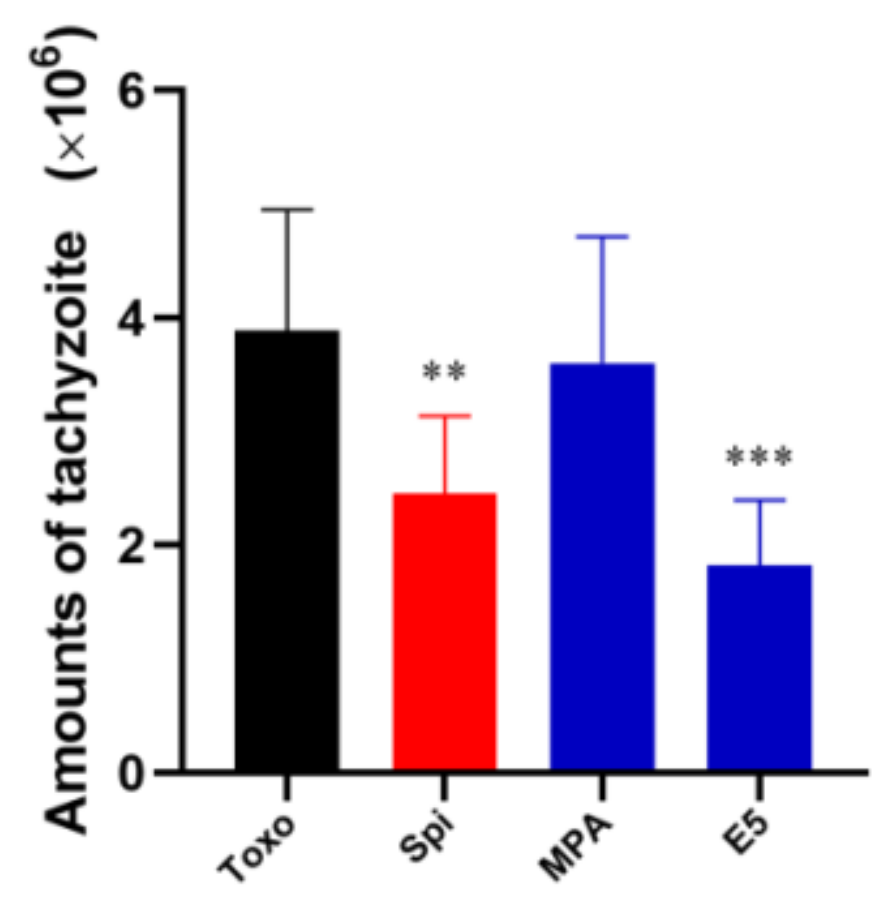

Figure 2

Number (Mean $\pm \mathrm{SD}$ ) of tachyzoites in the peritoneal cavity of mice treated with the test compounds, $\mathrm{n}=$

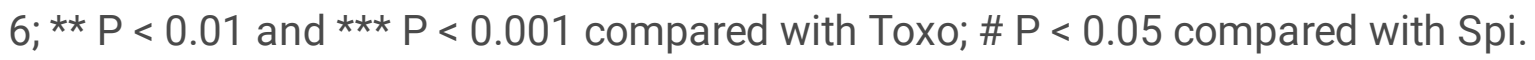
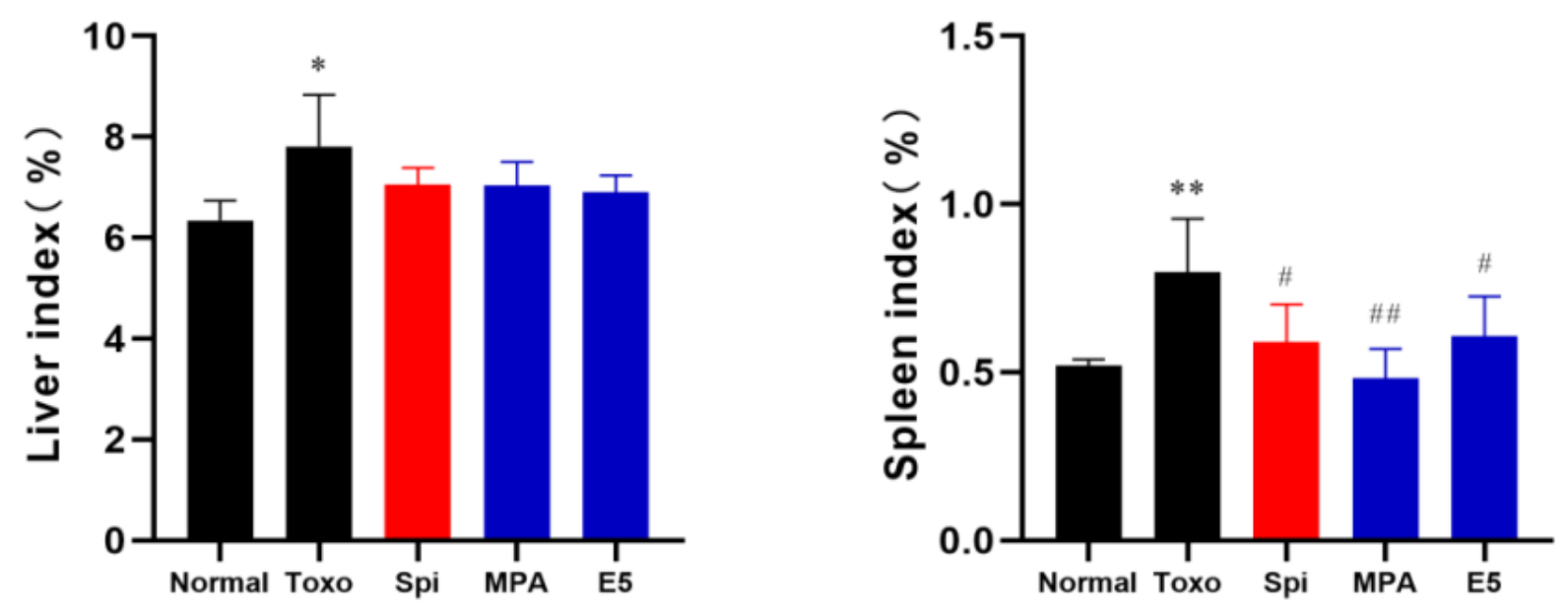

Figure 3 
Effects of the test compounds on relative organ weights in Toxoplasma gondii-infected KM mice. Values are expressed as mean \pm S.D. $(n=6)$. ${ }^{*} P<0.05$ and ${ }^{*} P P<0.01$ compared with normal; \# $P<0.05$ and \#\# $\mathrm{P}<0.01$ compared with Toxo.

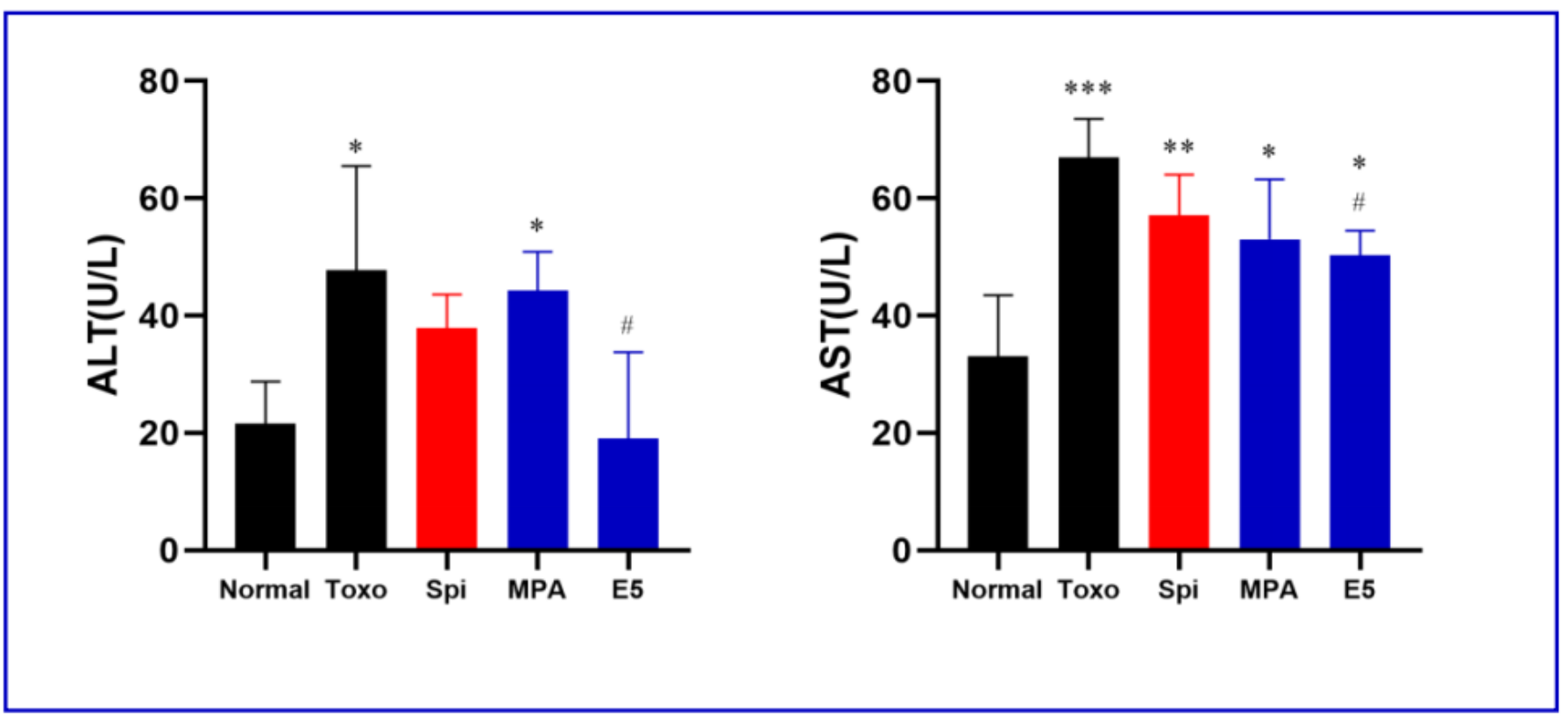

Figure 4

Effects of the text compounds on ALT and AST levels in Toxoplasma gondii-infected KM mice. Values are expressed as mean \pm S.D. $(n=6) .{ }^{*} P<0.05,{ }^{\star} * P<0.01$ and ${ }^{\star \star \star} P P<0.001$ compared with normal; $\# P<$ 0.05 compared with Toxo.
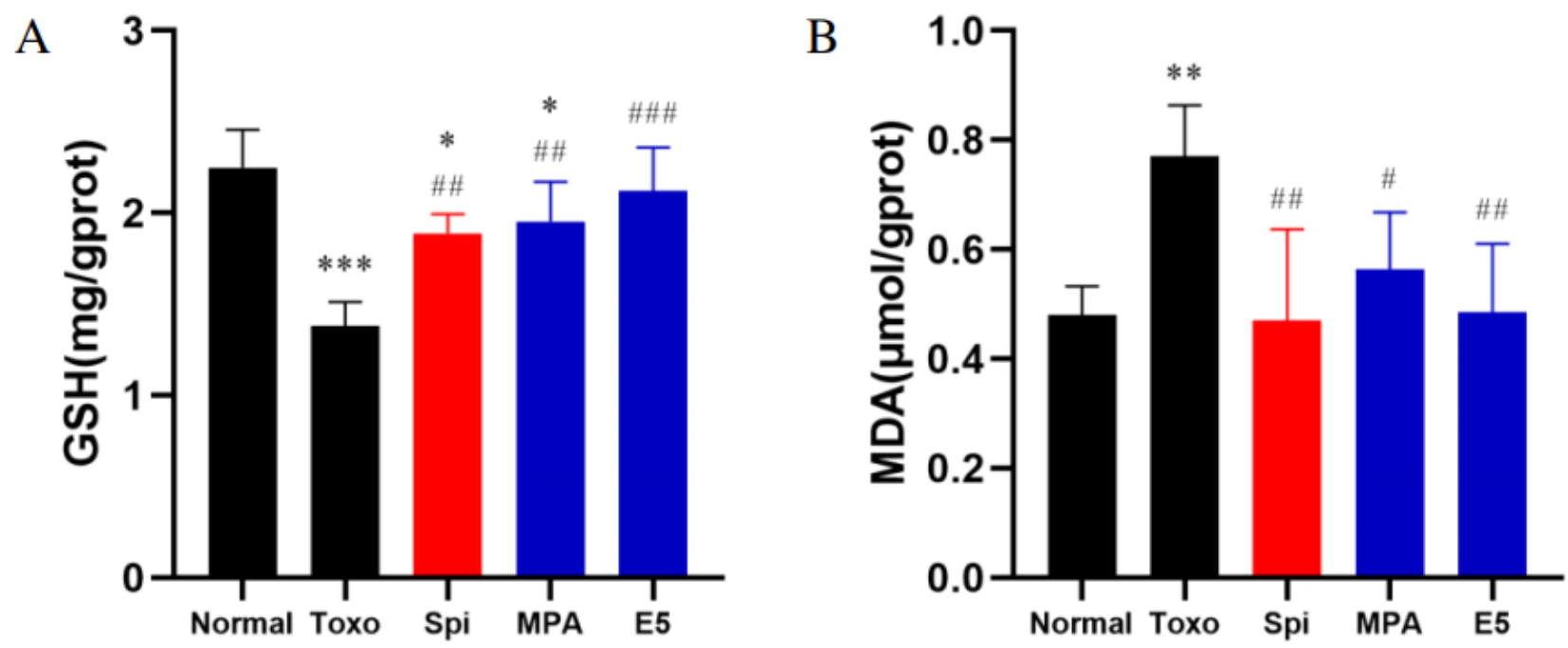

Figure 5 
Effect of the test compounds on GSH and MDA levels in Toxoplasma gondii-infected KM mice. Values are expressed as mean \pm S.D. $(n=6)$. ${ }^{*} P<0.05, \star \star P<0.01$ and $* \star \star P<0.001$ compared with normal; \# $P<$ 0.05 , \#\# $\mathrm{P}<0.01$ and \#\#\# $\mathrm{P}<0.001$ compared with Toxo.

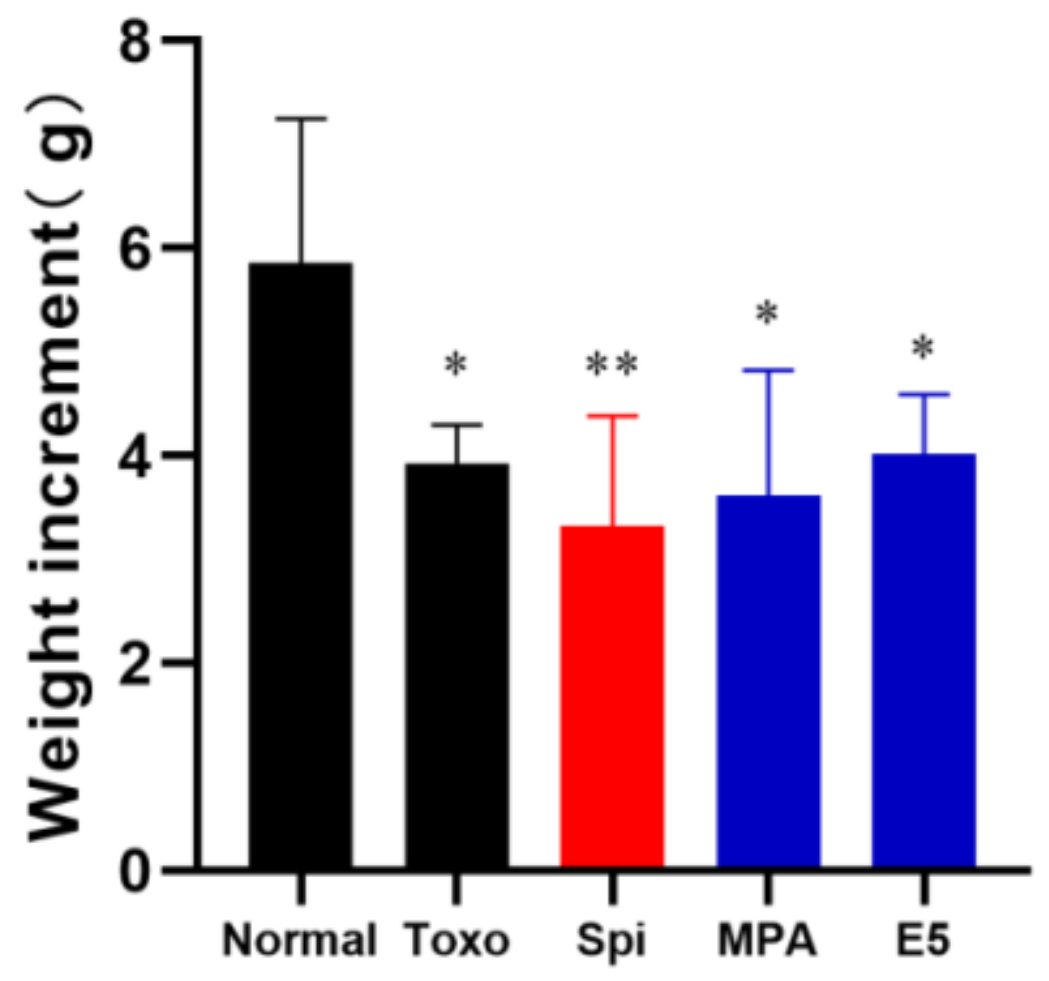

Figure 6

Effect of the test compounds on the body weights of Toxoplasma gondii-infected KM mice. Values are expressed as mean \pm S.D. $(n=6) .{ }^{*} P<0.05,{ }^{\star} * P<0.01$ and ${ }^{\star \star *} P<0.001$ compared with normal; $\# P<0.05$ compared with Toxo.

\section{Supplementary Files}

This is a list of supplementary files associated with this preprint. Click to download.

- Supplementarymaterials.docx

- Tables.pdf

- Scheme1.png 